\title{
Integrated Digital Learning Environment for IoT (IDLE-IoT): Teaching IoT through projects
}

\author{
Renan Yamaguti, Luiz Carlos Branquinho Caixeta Ferreira, Omar Carvalho Branquinho and Paulo \\ Cardieri
}

\begin{abstract}
Teaching has employed more and more digital and online tools, especially nowadays with the COVID-19 pandemic. IoT has beennotoriously troublesome for teaching due to its multidisciplinarynature, involving fields such as computing, electrical engineering, business, humanities studies, and others. Several methodologies have been developed to teach IoT and create solutions, including the Three Phase Methodology (TpM). This paper presents the development of an Integrated Digital Learning Environment (IDLE-IoT), for distance teaching of IoT, based on TpM and Bloom's Taxonomy, integrated with a hardware platform.
\end{abstract}

Keywords - Internet of Things, Teaching, Project, Bloom's Taxonomy, web development

\section{INTRODUCTION}

The Internet of Things (IoT) has been applied to a variety of different areas of human endeavors, from biology to technology, social sciences, and human health. Any IoT solution is intimately related to a problem to be solved and to a business in which this problem is inserted. Therefore, the development of anIoT solution is an inherently heterogeneous activity, requiring expertise in many different areas, including the one related to the problem itself, computing, communications, networking, and electronics. Such heterogeneous nature of IoT requires the engagement of professionals from different areas to design IoT solutions. Also, it imposes several challenges to teaching IoT, as well as the process of designing and developing IoT solutions. An alternative to tackle these challenges is the Three Phase Methodology (TpM), recently proposed by Ferreira et. al [1]. This methodology applies Project-Based Learning (PBL) concepts, with a broader view of the IoT applicationin mind, from the related business to issues related to the application's actual deployment. Although TpM is a promising methodology, it lacks a dedicated tool to be employed in its full capacity, due to its complex nature.

The COVID-19 pandemic has changed the teaching landscape, moving towards online teaching, motivating the development of several new online teaching environments. Despite the vast array of teaching environments available nowadays, none has proven to be a perfect match for TpM, nor has an integrated hardware platform in which students could implement their IoT projects. This paper presents an Integrated Digital Learning Environment (IDLE-IoT) intended to fill this gap.

Even though online teaching has shown to be a great tool, the students' lack of activity and the increasing dropout rate

Renan de Oliveira Yamaguti, University of Campinas, Campinas-SP, e-mail: renan.o.yamaguti@gmail.com; Luiz Carlos Branquinho Caixeta Ferreira, University of Campinas, Campinas-SP, e-mail: carlinho@decom.fee.unicamp.br; Omar Carvalho Branquinho, Campinas-SP, e-mail: omar.branquinho@gmail.com; Paulo Cardieri, University of Campinas, Campinas-SP, e-mail: cardieri@unicamp.br. are the side effects associated with this teaching environment. The IDLE platform proposed in this paper addresses the issue of student passivity, by placing students as the protagonists of their classes. The goal of the IDLE-IoT is to innovatein the IoT teaching field and apply TpM concepts, so ultimately students become project leaders and developers. Hence, the IDLE platform leads to the following benefits:

- Full use of TpM on each of its courses

- Utilization of an array of teaching techniques to innovate in IoT teaching

- An environment where the creation and sharing of projects can be guided by TpM

- A single environment for learning and project sharing

This paper is organized as follows: Sec. II briefly discusses the available platforms and the motivation for developing the IDLE; the theoretical basis is presented in Sec. III, upon which the IDLE platform is built; Sec. IV presents theproposed platform; some details of the implemented platform are presented in Sec. V; Sec. VI presents the conclusions.

\section{OTHER Similar PLATFORMS}

In today's pandemic (COVID-19) scenario, the primary teaching method has been distance learning. Bloom's taxonomy has been applied in some learning platforms [2], especially at high-school level [3]. These platforms, such as Google Classroom and Moodle, despite offeringcustomizable features, have yet to be integrated to both PBL techniques and Bloom's taxonomy in crowd-sourcing-based courses. Moodle has areas for forums, where students canshare their ideas [4].

However, this is not enough to apply $\mathrm{TpM}$ in its full capability, alongside PBL and in a crowd-sourcing-based environment. In conclusion, the classic and state-of-the-art Digital Learning Environments (DLE) limit the use of TpM alongside Bloom's Taxonomy. This scenario motivated the developmentof IDLE.

\section{THEORETICAL BASIS}

\section{A. Three Phase Methodology}

The Three Phase Methodology [1] is a methodology for IoT development and teaching. It was created based on the characteristics and needs of the process related to learning how the Internet of Things works. TpM is the main guideline of the IDLEIoT, as one of the objectives of the IDLE-IoT is to be an environment where TpM is applied to teach and guide project development. 
In [1], the authors present the TpM in its conceptual form, without suggesting any specific tool to implement such concepts. TpM is based on Project Based Learning (PBL), whereas the learning process is guided by a real- life project. PBL is a learning approach, where open solutions and challenging questions are adopted, in order to create products and improveprocesses, using the theoretical basis applied to daily life [5]. This strategy induces students to collect data and ideas, in addition to identifying issues related to the problem at hand that are unclear for them, therefore requiring in-depth study. This entire search process is supervised by an instructor, and with those answers and the theoretical support, the students are able to conclude their project and learn severalsubjects.[6].

The three phases of TpM are:

- Phase 1 - Understanding the Business,

- Phase 2 - Requirement Definition,

- Phase 3 - Implementation.

The "Understanding the Business" phase addresses the objectives of the IoT application at hand, and its main objective is to clearly define the problem to be solved before selecting any technology. Four aspects of the business related to the IoT application must be studied and defined in this phase:

- Business: The business behind the IoT solution mustbe clearly understood.

- Business Rules: The following question must be addressed: What are the rules and guidelines that makethe business work, such as, conditions and definitions of alarms and criteria of decision making?

- Specialist: Professional(s) with knowledge about the business' field must be consulted to help elaborate the Business Rules.

- The Things: Information, metrics and other details that must be monitored and controlled in order to provide the data required to solve the problem at hand.

Phases 2 and 3 are based on the IoT Open Source Reference Model (IoT-OSRM) [7], which is a generic reference model designed to be independent of manufacturers and technologies. This reference model defines six levels to connect things to the Business, as shown in Fig. 1, described as follows:

- Level 1 - Sensor Node/Actuator: The devices responsible for gathering/controlling the application's Things.

- Level 2 - Connectivity: This level is responsible for the connection between the Things and Level 3 (Border), using some communication technology (wireless communication, cables, etc.)

- Level 3 - Border: This element connects the local network of things and the remote network. At this element, data from the things may be pre-processed and stored as well.

- Level 4 - Storage: Data are stored here and their components are defined by the requirements and rules of the application (i.e., how data must be stored).

- Level 5 - Abstraction: at this layer, data are processed and transformed into a suitable format for use.

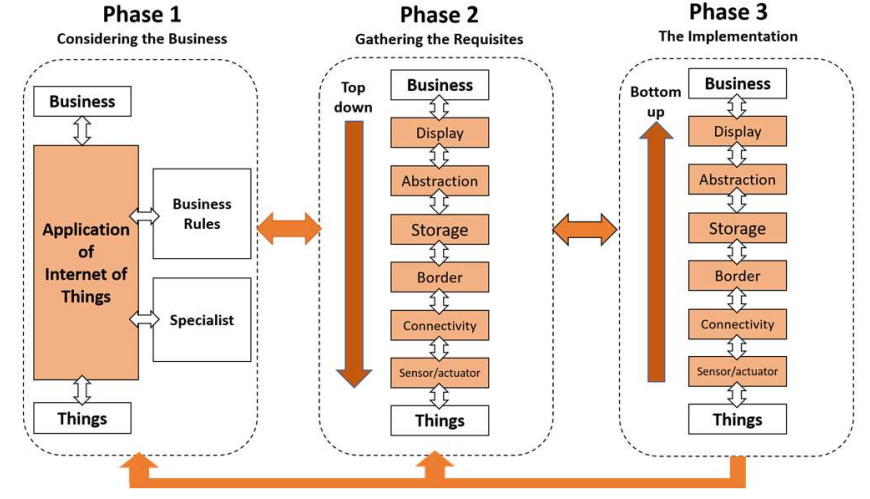

Fig. 1. The Three-Phase Methodology diagram encompassing the 6-level IoT-OSRM (adapted from [7]).

- Level 6 - Display: deals with how the information is shown to the end user.

The objective of the "Requirement Definition" $\mathrm{ph}$ a s e is to determine the requirement of each level of the reference model. Note that this phase precedes the selection of the technologies to be used to implement the components of each level.

In Phase 3, "Implementation", the technologies and techniques to implement the IoT solution are chosen, guided by the requirements defined in the previous phase.

As a final note, the rationale behind the TpM structure is that the development of any IoT solution must begin with a deep understanding of the business in which the IoT solution will be used and the end user's needs. This deep understandingwill guide the requirement definition and implementation.

\section{B. Bloom's Taxonomy}

The learning environment proposed in this paper uses the Bloom's Taxonomy [8], which is a hierarchical model to classify the learning process into levels of complexity. Bloom's Taxonomy defines three sets of models or domains: Cognitive, Affective, and Psychomotor. However, for distanceteaching, only the Cognitive domain is considered. The Cognitive domain is divided into six levels [9]:

- Remembering: when students are expected to recall and recognise previously learned knowledge;

- Understanding: students interpret and summarise what they have learned;

- Applying: students examine their understanding of a given subject;

- Analysing: in this phase, the correlation among what students have learned is identified;

- Evaluating: students discuss, test, and validate what they are learning;

- Creating: in this final phase, students produce new or original knowledge.

\section{THE IDLE Platform}

\section{A. Concepts of the Proposed Platform}

The proposed platform was built on three pillars, namely: (i) it must be an environment where TpM can be applied in 
its full capacity; (ii) it must guide content developers andcourse conductors alike to apply Bloom's taxonomy, and

(iii) it must integrate the learning platform to hardware for IoT teaching. Five users' roles are defined, and the learning process includes both synchronous and asynchronous learning moments.

Next, we describe the role and privileges of each type of users in Sec. IV-B, and the moments of learning in Sec. IVB. The three pillars of IDLE-IoT are discussed in the subsequent sections.

\section{B. Roles}

All IDLE users must be previously registered and classified into five categories: Student, Content Creator, Conductor, Designer, and Administrator.

(a) Student: Students are the protagonists of the courses, responsible for the dynamics of the classes. They are in charge of determining when the course conductor may proceed with the class.

(b) Content Creator: This user is the "heart" of the IDLE-IoT platform, as they are responsible for creating content in a structured manner, considering the course and the dynamics of the classes. They are responsible for applying Bloom's Taxonomy in each piece of content created.

(c) Conductor: The Conductor seeks to promote students' unique capacities, responsible for bringing to life the content developed by the Content Creator. The content is available through guided online classes. The Conductor has to be able to communicate with students from different backgrounds and areas. Once the course is finished, the Conductor is then evaluated by students and must evaluate the content created by the Content Creator.

(d) Designer: This user is responsible for creating and sharing projects. Under this role, the user has permission to write their IoT projects following TpM rules [1]. Such projects can be shared with other users, either for evaluation or for consulting and tips. All students are encouraged to be designers, but this role is not restricted to students. IoT enthusiasts and professionals can create and share projects, turning this platform intoa hub of projects.

(e) Administrator: This user "oversees" the platform. For instance, the administrator is responsible for approving applications for new Conductors and Content Creators, as well as monitoring scores and rates of all courses available in the platform.

\section{Moments of Learning}

Courses have two moments of learning: Synchronous and Asynchronous moments.

- Synchronous moments: These moments are similar to classic online classes, when students are introduced to the course content and to additional materials. Students are challenged to think on the fly and follow the suggested theme of the class. However, the flow of the class is controlled by students, by using an ' $\mathrm{OK}$ ' button - the Conductor is allowed to proceed only when all students agree. The courses offered under this moment of learning are the online Courses.

- Asynchronous moments: These moments represent two categories of courses: the offline courses and the shortcourses. In offline courses, students conduct their own classes, according to their own pace. Offline courses are recorded by the Conductor and uploaded in a structured manner in the IDLE-IoT platform. Short-courses, on the otherhand, are droplet courses, consisting of a single video (no longerthan 10 minutes) and additional materials.

\section{First Pillar: Application of TpM}

As previously mentioned, one of the main purposes of the IDLE-IoT platform is to provide an environment where the TpM methodology can be fully applied. That is achieved by having all courses carried out using the so-called conductor project, which is the project of an IoT solution designed and developed by students throughout the course, serving as a guideline to introduce all key concepts of any IoT solution. The Content Creator is responsible for specifyingthe conductor project, evidencing which levels (or layers) of the reference model [7] are covered in that particular course. Note that the same conductor project can be used in different courses, each exploring a different application.

\section{E. Second Pillar: Use of Bloom's Taxonomy}

The courses must be divided into modules and classes in a way to implement Bloom's Taxonomy.

1) Modules: Modules are the first level of division of courses, specialized and intertwined with TpM. Throughout the course, students should be able to recognize which level of the TpM structure they are dealing with. Subjects that are included in a given level should be incorporated into the same module. We suggest that the first module should introduce and review TpM concepts andthe selected conductor project, while the last module shouldbe dedicated to course evaluation.

2) Classes: Each module consists of at least one class, and a class must contain the following seven components:

(i) Thinking about a problem: In the first part of a class, students are introduced to a problem, and asked to think about a solution to that problem based on IoT.

(ii) Defining the objective: After thinking about the problem, students are presented to the goal of the class and how to apply IoT solutions to solve the problem.

(iii) Material needed to solve the problem: Once the problem is defined and the objective is established, students must determine the materials needed to develop the IoT solution.

(iv) Knowledge required to solve the problem: During this part of the class, students start to analyze the problemat hand and what $\mathrm{knowledge}$ is needed to solve it. Thisis the moment when most of the theoretical content is discussed. 
(v) What you need to do: at this moment, the conductoralmost "disappears", and students must exercise their autonomy by being left to think for themselves. They must be encouraged to figure out the correlation among the previous phases of the course and to evaluate what has been discussed. Students must then outline their plan and think as a team, abstracting what has already been discussed.

(vi) Interpreting results: After the discussion carriedout in the previous part of the class, students are invitedto analyze and interpret the results and conclusions ofthe discussion. Such analysis is crucial to consolidate students' critical thinking [9] and convince them of the proposed solution.

(vii) Proposal: In the last part of each class, studentsmust propose new IoT solutions based on what has been discussed in previous parts. The solutions are then submitted for evaluation, creating a dynamic environment among students.

\section{F. Third Pillar: Hardware Integration}

The IDLE platform is integrated with a baseline hardware known as PK Family (see Fig. 2). The PK family consists of

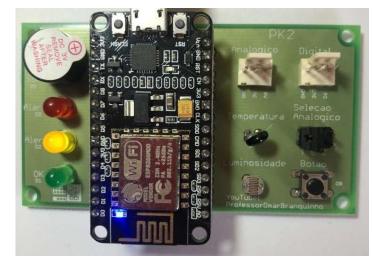

Fig. 2. Hardware platform PK2, integrated with the IDLE platform.

an Arduino, temperature sensor, luminosity sensor (LDR), a buzzer, three LEDs, an analog and digital ports, all integrated into one board. The integration between PK2 and the IDLE platform, through an Arduino editor and compiler, allows students to develop their IoT solutions without requiring prototype boards and wired connections.

\section{IMPLEMENTATION OF IDLE}

The IDLE platform is freely accessible at www.iotm 3 f.cc (see Fig. 3) (registration required), making it available to everyone interested in learning how to develop an IoT solution. In fact, collaborative work on the platform is

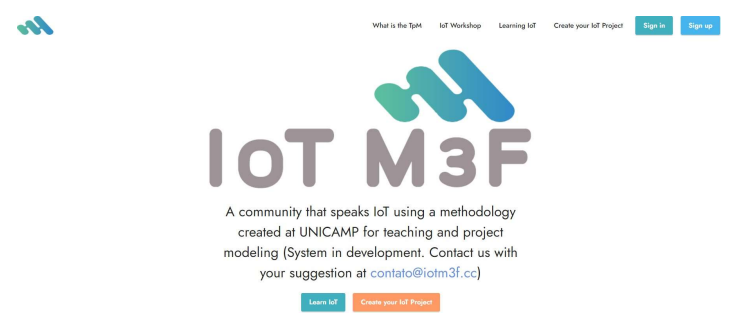

Fig. 3. IDLE landing page.

encouraged, to create a community dedicated to teaching
IoT concepts and developing IoT solutions, based on the principles of TpM.

In the following subsections, we present the view of the system from the perspective of each class of user.

\section{A. User views}

1) Student's View: Once logged in to the platform, students are directed to a page (see Fig. 4) on which they can either read the blog, with news and other related articles, or select a course to follow. In the courses tab, it is possible to watch

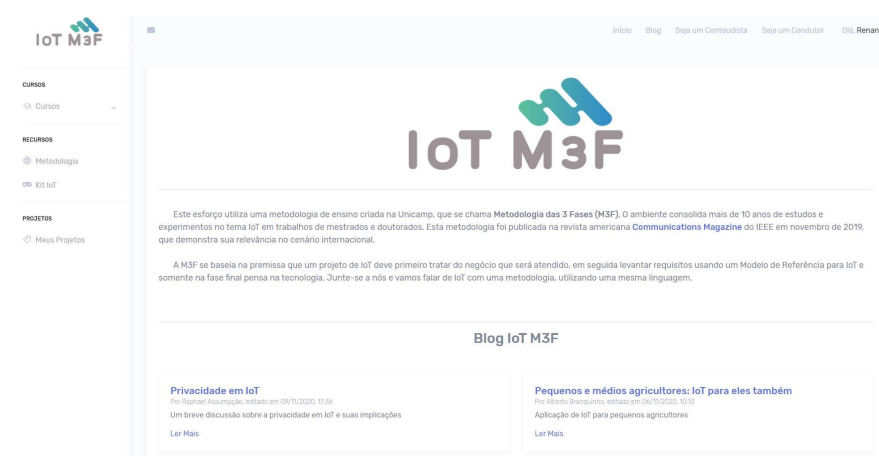

Fig. 4. System's sharing project page.

live classes, as illustrated in Fig. 5

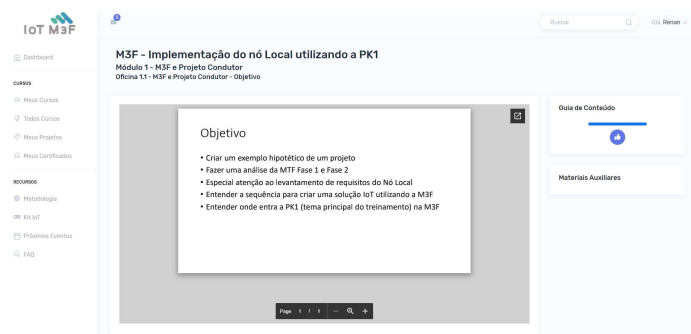

Fig. 5. Screenshot of a live class.

2) Designer's View: Once a user clicks on the project tab, they are directed to the screen shown in Fig. 6. On this page,

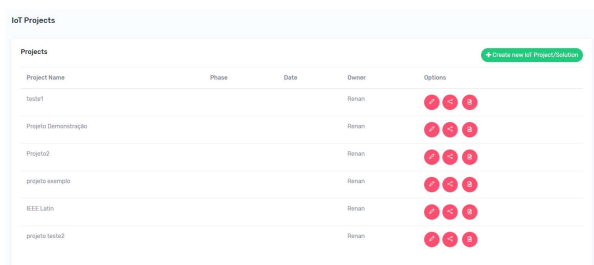

Fig. 6. System's sharing project page.

the user can create a new project or share an existing project with other users. After editing a project or adding a new one, a new navigation page shows up. The navigation through the phases of the methodology follows the principles of TpM. Students are required to follow the path established bytshe TpM methodology at least in the first cycle of interaction. A given phase is unlocked only after the student fills in the fields of the previous phase in the proper order. Fig. 7 shows the flowchart that must be followed by students. 


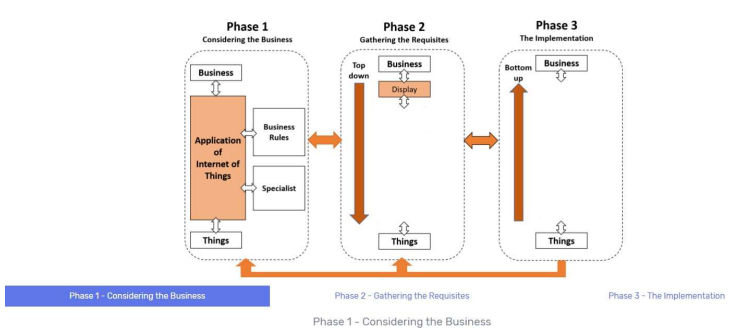

Fig. 7. Flowchart of steps that students must follow.

3) Conductor's View: The conductor has permission to access a tab dedicated to conduct a course in the established time. This tab is not available to other users. An example of an online class can be seen in Fig. 8

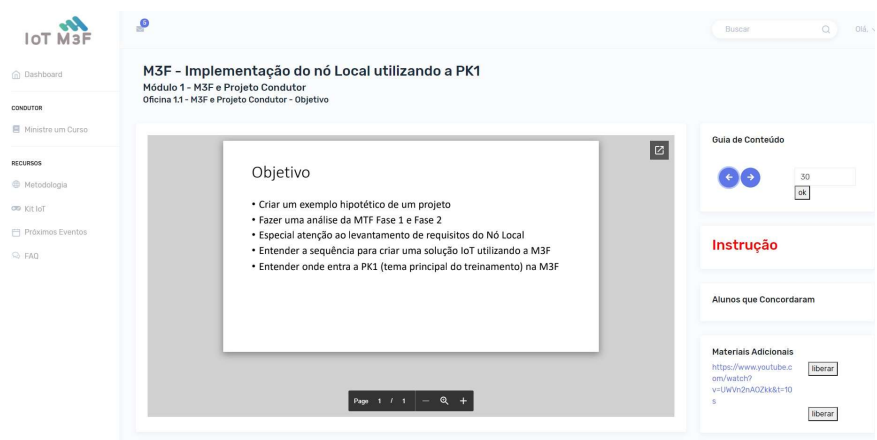

Fig. 8. Conductor's view of an online class.

4) Content Creator's View: Similar to the Conductor's view, the content creator has an exclusive tab. All courses created by the user are shown in this tab. These projectsare classified into three categories, as discussed in Sec. IV(i.e., online, offline, and short-courses). The Content Creator must create classes with all seven components, as detailed in Sec. IV. The platform shapes the contents in order to create a cohesive identity among the courses. Fig. 9 shows a snapshotof a page seen by the Content Creator while creating a course.

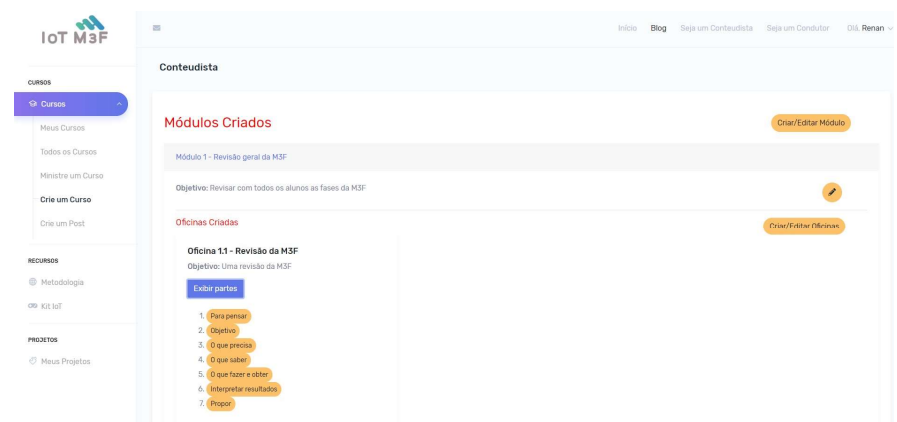

Fig. 9. Content's Creator view when creating a course.

\section{CONCLUSIONS}

This paper presented a collaborative Integrated Digital Learning Environment (IDLE-IoT) for teaching IoT, based on TpM and Bloom's Taxonomy. The objective of this environment is to contribute to and innovate in the field of IoT teaching, project development, and documentation, placing students as the protagonists of classes. The system isfree-to-use and readily available to the community at the web address www.iotm3f.cc. Its dissemination and use by the IoT community may contribute to the standardization of the use of $\mathrm{TpM}$ in teaching and project development.

\section{REFERENCES}

[1] L. C. B. C. Ferreira, O. C. Branquinho, P. R. Chaves, P. Cardieri, F. Fruett, and M. D. Yacoub, "A pbl-based methodology for iot teaching," IEEE Communications Magazine, vol. 57, no. 11, pp. 20-26, 2019.

[2] M. B. Gilboy, S. Heinerichs, and G. Pazzaglia, "Enhancing student engagement using the flipped classroom," Journal of nutrition education and behavior, vol. 47, no. 1, pp. 109-114, 2015.

[3] R. Ramadhani, U. Rofiqul, A. Abdurrahman, and M. SYAZAL I, "The effect of flipped-problem based learning model integrated with lms-google classroom for senior high school students," Journal for the Education of Gifted Young Scientists, vol. 7, no. 2, pp. 137-158, 2019.

[4] N. Morze, L. Varchenko-Trotsenko, T. Terletska, and E. SmyrnovaTrybulska, "Implementation of adaptive learning at higher education institutions by means of moodle lms," in Journal of Physics: Conference Series, vol. 1840, p. 012062, IOP Publishing, 2021.

[5] C. d. C. BASTOS, "Metodologias ativas. 2006," Accessed on 28/08/2019, vol. 1, 2017.

[6] L. C. de Campos, "Análise das abordagens pbl e ple na educação em engenharia com base na taxonomia de bloom e no ciclo de aprendizagem de kolb," International Journal on Alive Engineering Education, vol. 1, no. 1, pp. 37-46, 2014.

[7] A. L. B. Déo, "Proposal of an open source reference model for iot," Master's thesis, Pontifical Catholic University of Campinas, Brazil, December 2018.

[8] D. R. Krathwohl, B. S. Bloom, and B. B. Masia, Taxonomy of educational objectives: the classification of educational goals; Handbook II: Affective Domain. David McKay Company, Incorporated, 1956.

[9] D. R. Krathwohl, "A revision of bloom's taxonomy: An overview," Theory into practice, vol. 41, no. 4, pp. 212-218, 2002. 